Article

\title{
Sensitivity Analysis of Window Frame Components Effect on Thermal Transmittance
}

\author{
Giorgio Baldinelli ${ }^{1} *\left(\mathbb{D}\right.$, Agnieszka Lechowska ${ }^{2}$, Francesco Bianchi ${ }^{3}$ and Jacek Schnotale ${ }^{2}$ (i) \\ 1 Department of Engineering, University of Perugia, Via Duranti, 67-06125 Perugia, Italy \\ 2 Department of Environmental and Power Engineering, Cracow University of Technology, \\ ul. Warszawska 24, 31-155 Cracow, Poland; agnieszka.lechowska@pk.edu.pl (A.L.); \\ j.schnotale@gmail.com (J.S.) \\ 3 Department of Physics and Geology, University of Perugia, Via Pascoli, 06123 Perugia, Italy; \\ francesco.bianchi@unipg.it \\ * Correspondence: giorgio.baldinelli@unipg.it; Tel.: +39-075-585-3868; Fax: +39-075-585-3697
}

Received: 6 May 2020; Accepted: 6 June 2020; Published: 9 June 2020

\begin{abstract}
Standard ISO 10077-2 gives the procedure to calculate thermal transmittances of window frames in 2D numerical simulations. It also introduces some examples of frame geometrical models with all necessary input data and the solutions so as to perform validation of the applied numerical tools. In the present paper, the models prepared with a commercial finite volume software of a PVC window frame were first positively validated with the results given in the Standard. An experimental test was then implemented to confirm the simulated data, with satisfactory agreement. The numerical code was used on one of the frames provided by the Standard to perform a sensitivity analysis of all the components and boundary conditions playing a role on the definition of the frame thermal transmittance, such as surface heat transfer coefficients, values of the solid thermal conductivity, emissivity and insulation properties of air gaps. Results demonstrate that the air gap properties represent the most influential parameters for the definition of the PVC window frames thermal transmittance, followed by the surface heat transfer coefficients and the PVC thermal conductivity. The rubber and the steel properties show a negligible effect on the whole frame performance. This procedure could constitute a design tool to guide the efforts of window manufacturers for the achievement of high performance products.
\end{abstract}

Keywords: window frames; numerical analysis; hot box; sensitivity analysis

\section{Highlights}

- Numerical simulations of different window frames given in Standard ISO 10077-2 were performed.

- Measurements of window frame U-value in hot box apparatus with satisfactory agreement with simulations were performed.

- A surface response module in Ansys Fluent software was performed, indicating a strong impact of air gap properties on the window frame U-value.

- Numerical sensitivity analysis method proved a reliable tool to optimise window frames performance.

\section{Introduction}

The massive use of insulating materials on opaque walls makes windows the weakest part of the building envelope in terms of heat loss [1,2]. The transparent components performance have been strongly improved in recent years, both from the glazing and frame points of view [3-6]. The researchers 
also examined the edge-of-the-glass region to create better joint solutions $[7,8]$ but the efforts from researchers and manufacturers to lower the windows thermal transmittance are still needed [9].

Window frame thermal transmittance $\left(U_{f}\right.$ values) can be obtained both in numerical simulations and in measurements performed in the calorimetric chamber. Both methods are described in standards ISO 10077-2 [10] and EN 12412-2 [11], respectively. The computational approach could be implemented by software such as Frame Simulator [12], Therm [13], etc.

The standard ISO 10077-2, gives some examples of geometries of window frames with all the necessary input data and solutions (calculated $U_{f}$ values). The Standard obliges the users of the method to validate the applied calculation programs and to perform the calculations given in the examples. The users should achieve a level of discrepancy lower than $3 \%$ between the results of the calculations and the values given in the Standard. In the first part of the present work, the software Ansys Fluent [14] was validated with the ISO 10077-2 approach to calculate $U_{f}$ values. Fluent was chosen due to the capability of the code to implement optimization routines that allow a relatively quick calculation of a high number of frame design cases under investigation.

The robustness of the software results was further confirmed by measurements performed in standardized conditions in the calorimetric chamber, assessing the differences between the simulation and measurement results of an actual window frame thermal transmittance. After these steps, a sensitivity analysis [15] of the different parameters playing a role in the frame thermal transmittance was conducted. The investigation covered the boundary conditions (surface heat transfer coefficients on cold and warm sides), as well as material thermal conductivities and surface emissivity. The software allows automatic variation of the above-mentioned parameters within a user-defined range, in order to define the most influential ones on the window global performance. As far as the authors' knowledge, the sensitivity analysis approach has not been reported in previous studies and it could constitute a novel tool in the window frames design phase, covering a wide range of cases through simulations with a reasonable computational time.

Both calculations and experiments carried out in this research are valid only for steady-state conditions. The numerical models and the hot box measurements do not take into account the transient effect of boundary conditions (heat transfer coefficients, boundary temperatures, heat accumulation, overheating due to direct exposure to sunlight, etc.), which could play a significant role when the holistic performance of a window is analyzed.

\section{Analyzed Frame Models and Simulation Input Data}

The validation of the window frame thermal transmittance calculations took into account four chosen example models given in Standard ISO 10077-2 [10]: aluminum frame (example I1 from the Standard), PVC frame (example I3), a wooden frame (example I4) and a roof window wooden frame (example 15). The views of the models are given in standard [10]. An additional frame model was analyzed, which was a window frame made of PVC hosting a triple glazing [16] (Figure 1), which was also tested experimentally in a hot box apparatus.

All five models contain air gaps in the frames. The gaps were replaced by a solid with an equivalent thermal conductivity calculated according to Standard ISO 10077-2 [10] indications. Both convective and radiative heat transfer in the gaps were taken into account. The Standard [10] introduces the method of calculation including conductivity of air gaps when they are rectangular as well as when they are non-rectangular. In the latter case, the equivalent width, thickness and area of non-rectangular air gaps are calculated, and they are treated as rectangular, following the standard. The knowledge of surface temperatures of the gaps is required which implies an iterative process. In the first step, the gap surface temperatures were assumed and after heat exchange calculations they were corrected from the temperature distribution and the calculations were repeated again. After calculations of the equivalent values of a gap conductivity, the simulations treat all materials as solids. The material thermal conductivities are shown in Table 1. Surface emissivity was assumed as equal to 0.90 . When calculating 
window frame thermal transmittance, glazing has to be replaced with an insulation panel of the same thickness as glazing and a visible height of $190 \mathrm{~mm}$.

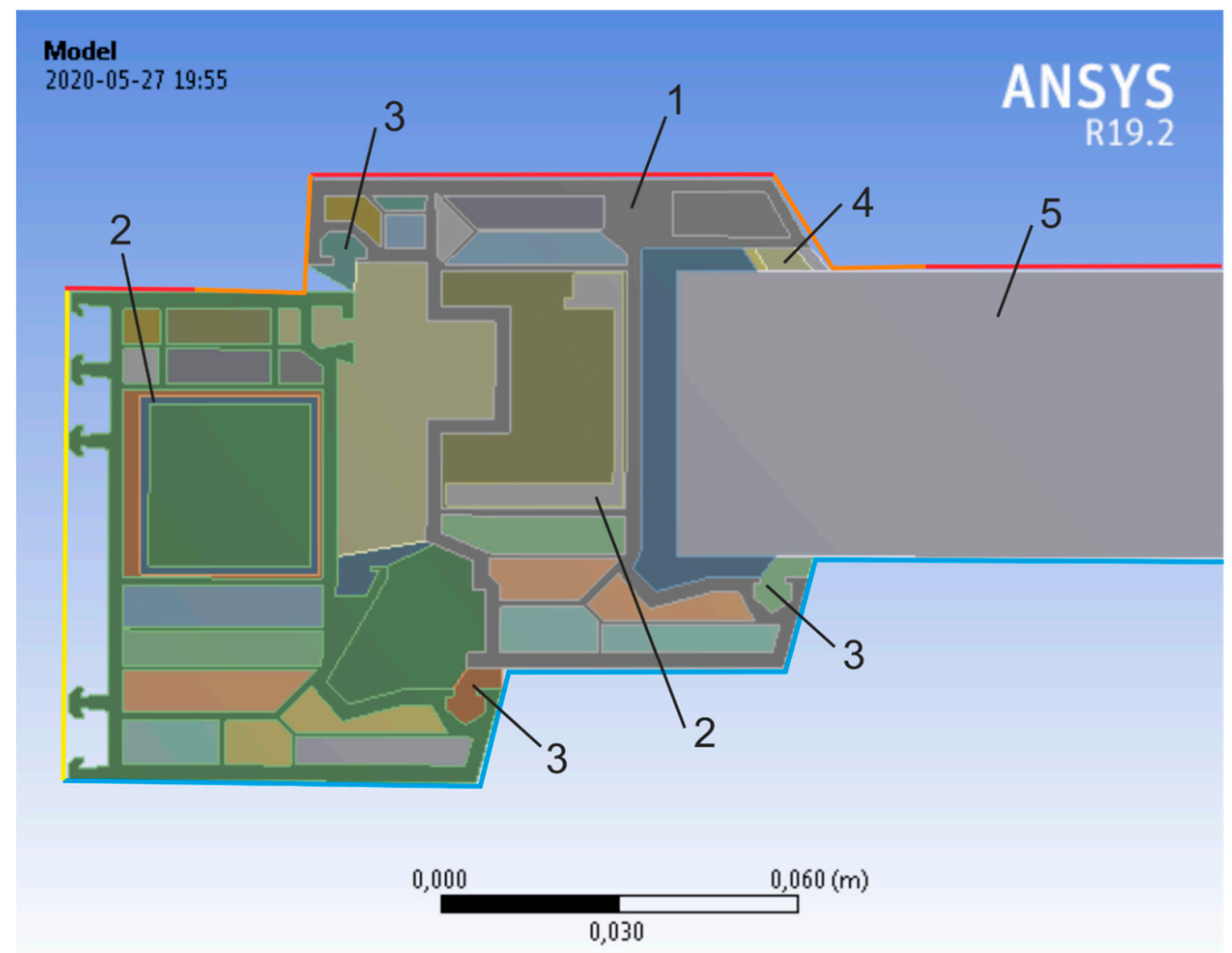

Figure 1. Model of real PVC frame with the following materials: 1, PVC; 2, steel; 3, ethylene-propylene diene monomer (EPDM); 4, butyl rubber; 5, insulation panel. Colored lines define the boundary conditions.

Table 1. Material thermal conductivities.

\begin{tabular}{cc}
\hline Material & Thermal Conductivity W/(mK) \\
\hline Wood & 0.130 \\
\hline PVC & 0.170 \\
\hline EPDM & 0.250 \\
\hline Aluminum & 160.0 \\
\hline Polyamide & 0.300 \\
\hline Steel & 50.0 \\
\hline Butyl rubber & 0.24 \\
\hline Insulation panel & 0.035 \\
\hline
\end{tabular}

Both the end of the insulation panel and the frame part adjacent to the wall were treated as adiabatic. On the internal (warm) side of the frame, the temperature of air $\theta_{i}$ was fixed at $20^{\circ} \mathrm{C}$, while on the external (cold) frame side, the air temperature $\theta_{e}$ was considered equal to $0{ }^{\circ} \mathrm{C}$, as suggested by the Standard [10]. As the Standard [10] assumes different values of heat transfer coefficients on boundaries, the choices taken in the domain are shown in Figure 1. The yellow boundary line shows 
adiabatic conditions on the end of the frame (left hand side). Blue lines show external boundary conditions with heat transfer coefficient equal to $25 \mathrm{~W} /\left(\mathrm{m}^{2} \mathrm{~K}\right)$, while red and orange lines represent internal boundary conditions with the values $7.7 \mathrm{~W} /\left(\mathrm{m}^{2} \mathrm{~K}\right)$ and $5 \mathrm{~W} /\left(\mathrm{m}^{2} \mathrm{~K}\right)$, respectively.

Ansys Fluent [14] program uses the finite volume method. The calculations were performed in steady-state conditions, with second order up-wind discretization scheme used for the energy equation.

The temperature distributions for five given geometries are presented in Figures 2-6.

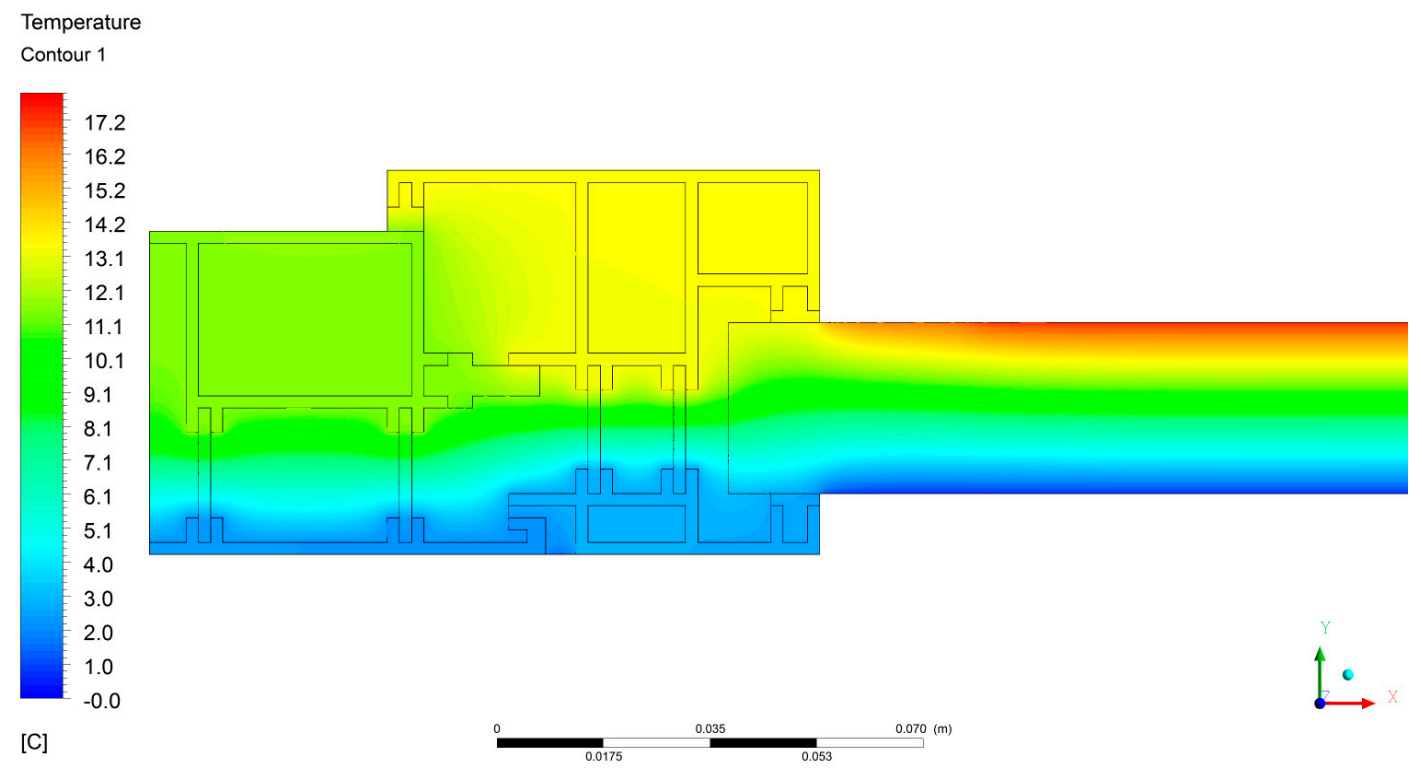

Figure 2. Temperature distribution on aluminum frame, example I1 from ISO 10077-2.
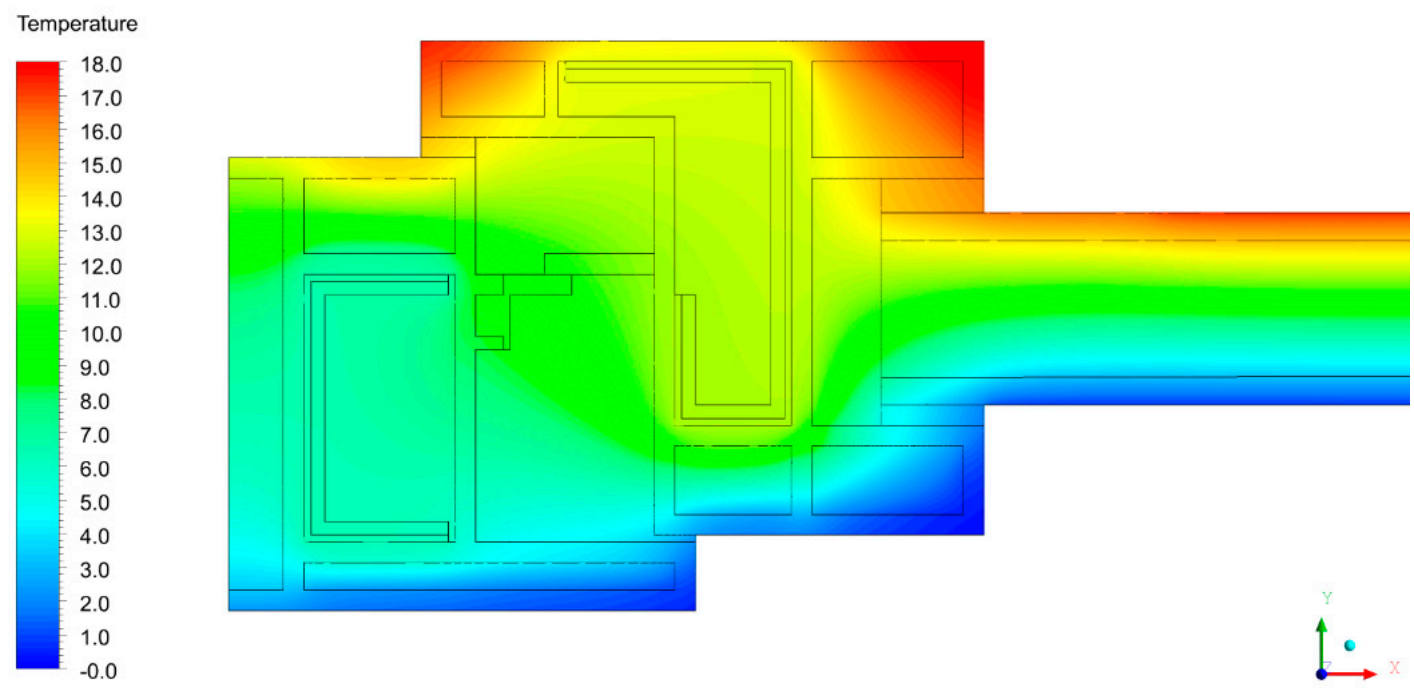

$[\mathrm{C}]$

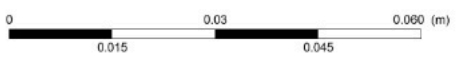

Figure 3. Temperature distribution on PVC frame, example I3 from ISO 10077-2. 

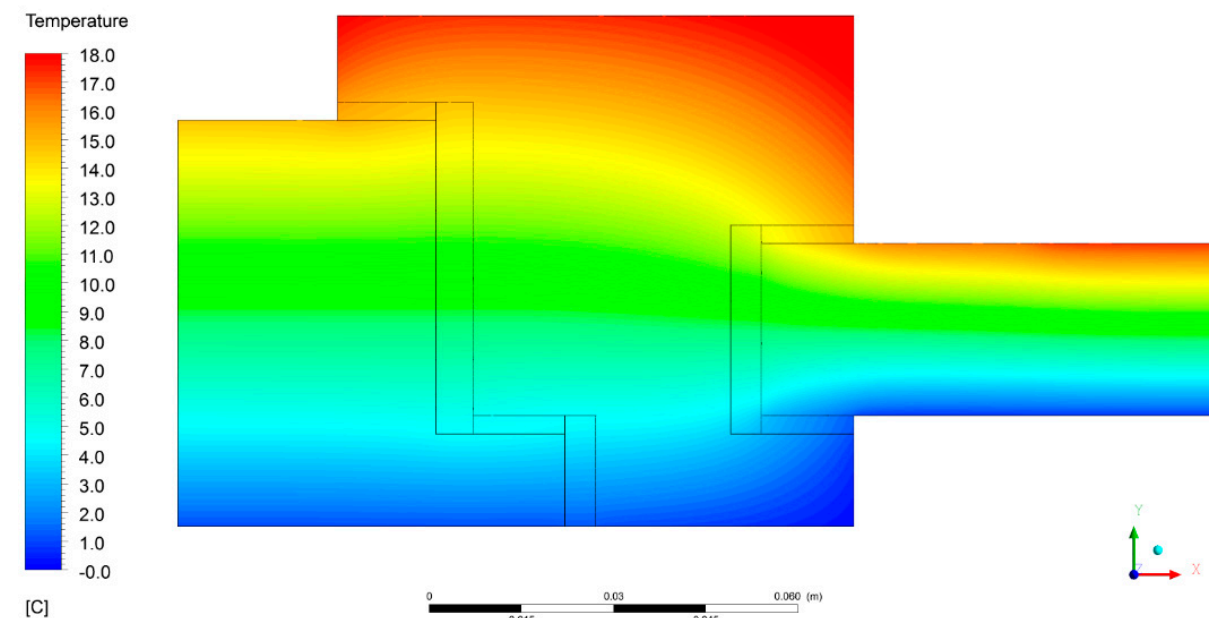

[C]

Figure 4. Temperature distribution on wooden frame, example I4 from ISO 10077-2.
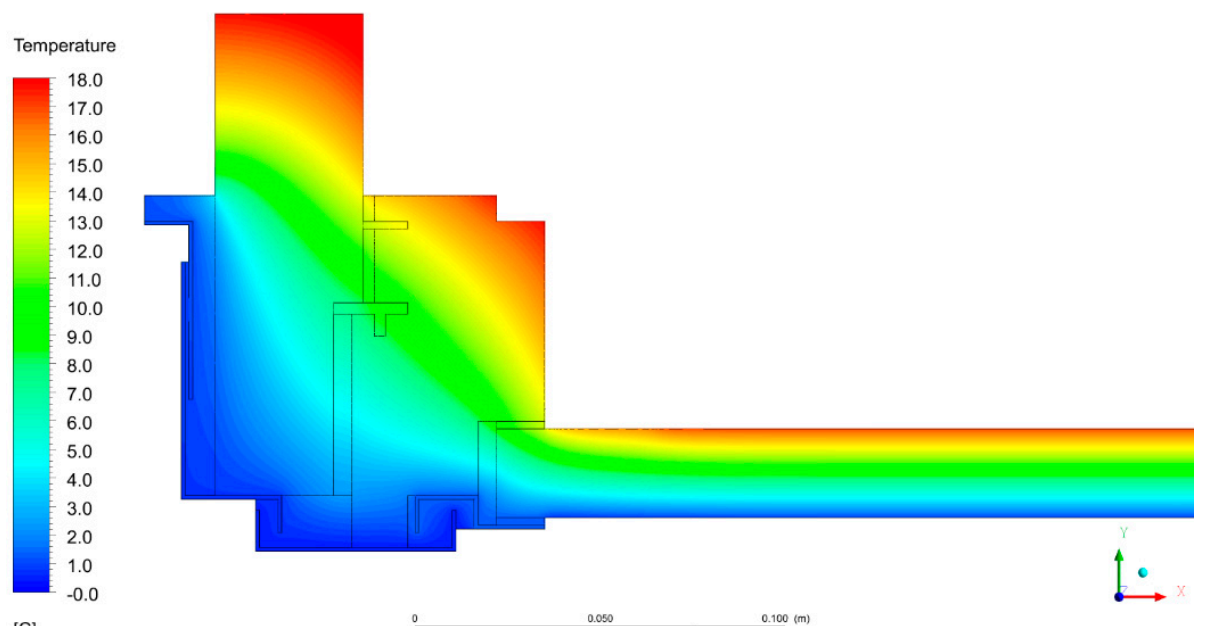

[C]

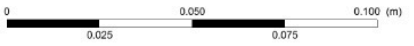

Figure 5. Temperature distribution on roof window frame, example I5 from ISO 10077-2.

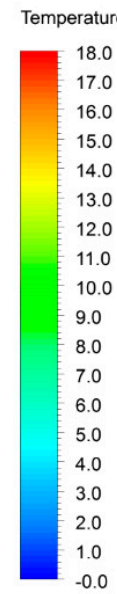

$[\mathrm{C}]$
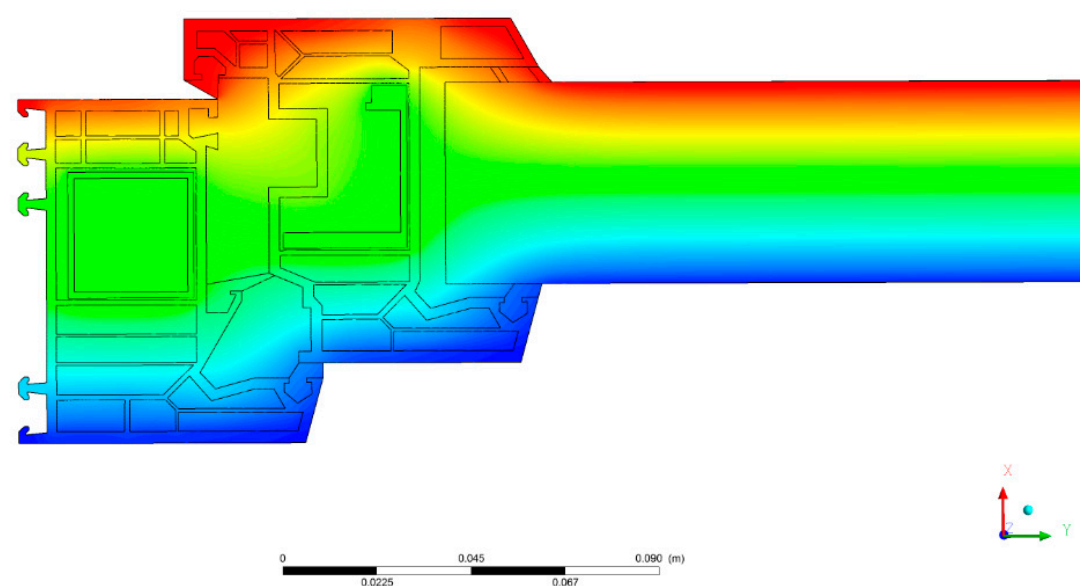

Figure 6. Temperature distribution on real PVC frame.

As can be seen in Figures 2-6, the temperature distribution in the part of glazing is one-dimensional (parallel isotherms), while in the frame the heat flux changes its direction. The warmer the frame 
on its internal side, the lower the value of frame heat losses. It can be seen that the aluminum one (example I1) is the coldest on its internal side, indicating the worst performance in terms of thermal transmittance (see the results in Table 2).

Table 2. Comparison of the simulation results and the results from the standard ISO 10077-2.

\begin{tabular}{|c|c|c|c|c|}
\hline Frame & Source & $\mathrm{L}_{\mathrm{f}}^{2 \mathrm{D}}, \mathrm{W} /(\mathrm{mK})$ & $\mathrm{U}_{\mathrm{f}}, \mathrm{W} /\left(\mathrm{m}^{2} \mathrm{~K}\right)$ & $\frac{\left|\mathrm{U}_{\mathrm{f}, \text { simul }}-\mathrm{U}_{\mathrm{f}, \text { stand }}\right|}{\mathrm{U}_{\mathrm{f}, \mathrm{s} \text { stand }}} \cdot 100 \%$ \\
\hline \multirow{2}{*}{ I1 } & Simulations & 0.550 & 3.22 & \multirow{2}{*}{$0.2 \%$} \\
\hline & Standard & $0.550 \pm 0.007$ & $3.22 \pm 0.06$ & \\
\hline \multirow{2}{*}{ I3 } & Simulations & 0.421 & 2.05 & \multirow{2}{*}{$1.0 \%$} \\
\hline & Standard & $0.424 \pm 0.006$ & $2.07 \pm 0.06$ & \\
\hline \multirow{2}{*}{ I4 } & Simulations & 0.345 & 1.35 & \multirow{2}{*}{$0.7 \%$} \\
\hline & Standard & $0.346 \pm 0.001$ & $1.36 \pm 0.01$ & \\
\hline \multirow{2}{*}{ I5 } & Simulations & 0.402 & 2.02 & \multirow{2}{*}{$2.9 \%$} \\
\hline & Standard & $0.408 \pm 0.007$ & $2.08 \pm 0.08$ & \\
\hline Real PVC frame & Simulations & 0.261 & 1.098 & Not applicable \\
\hline
\end{tabular}

\section{Simulation Results}

The window frame thermal transmittance was calculated from the following equation [10]:

$$
\mathrm{U}_{\mathrm{f}}=\frac{\mathrm{L}_{\mathrm{f}}^{2 \mathrm{D}}-\mathrm{U}_{\mathrm{p}} \mathrm{b}_{\mathrm{p}}}{\mathrm{b}_{\mathrm{f}}},
$$

where:

$$
\mathrm{L}_{\mathrm{f}}^{2 \mathrm{D}}=\frac{\Phi}{\theta_{\mathrm{i}}-\theta_{\mathrm{e}}}
$$

The results of the numerical calculations of five models are given in Table 2.

Results show that each simulation result differs less than $3 \%$ from the values given in the Standard [10]. Thus, it can be stated that the software Ansys Fluent [14] could be applied as a tool for window frame thermal transmittance calculations. The lower row of Table 2 is supplemented with the results of the simulations of the fifth model, whichh is a real PVC window frame hosting a triple glazing.

\section{Window Frames Thermal Transmittance Measurements}

The second stage of the work was focused on the measurements of window frame thermal transmittance and comparison of the experimental results with the simulations for validation.

The frame measurements should meet the demands of the Standard EN 12412-2 [11] and should be performed in a calorimetric chamber (Figure 7). This device consists of two spaces separated with a surround panel, which consists of a cold chamber and a warm chamber. The specimen to be tested was mounted into the surround panel, which was made of thick insulation material with known thermal conductivity. In the case of window frame thermal transmittance measurements, the glazing was substituted by an insulation panel with (known) low thermal conductivity, and the same thickness as the glazing. 


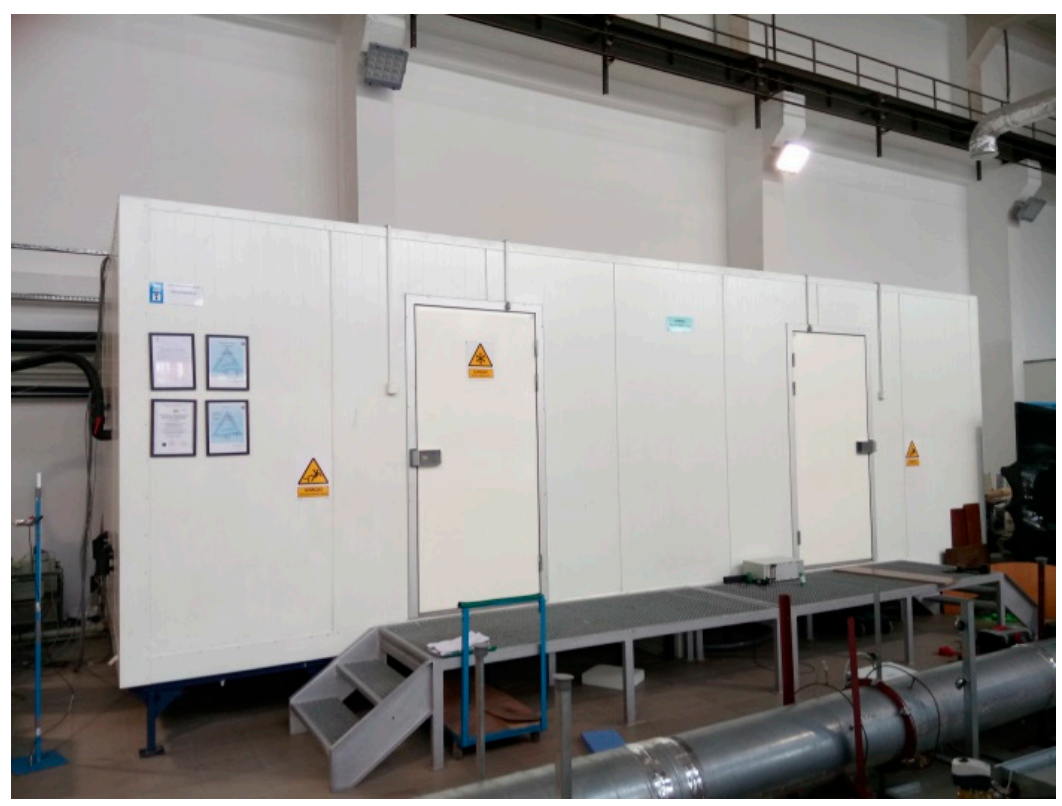

Figure 7. The view of the Laboratory of Thermal Engineering calorimetric chamber situated in Cracow University of Technology, Poland.

In the cold chamber, the air was kept in steady-state thermal conditions $\left(0^{\circ} \mathrm{C}\right)$, through a control and data acquisition system. The same approach was used in the warm chamber, where the air temperature set point was fixed to $20^{\circ} \mathrm{C}$. The test specimen cold side faced a baffle. A set of ventilators was installed on the top of the baffle to push the air upwards in controlled forced convection conditions on the space between the baffle and the specimen. The heart of the measurement stand is the hot box system. It is a smaller guarded chamber embracing the specimen on its warm side. In the lower hot box part, ventilators were installed in order to move the air downwards along the tested specimen, to create steady-state natural convection conditions. The hot box was equipped with internal radiators. The idea of the measurement is that the radiators provide the amount of heat demanded to ensure the temperature difference between the internal and the external hot box walls is $0 \mathrm{~K}$, i.e., no heat is transferred through the hot box walls. That means that all heat power from the radiators is supplied to the specimen, to the surround panel and to the flanking losses between them [16,17].

After more than three hours of steady-state conditions in the whole apparatus, the temperatures of air, surface temperatures of baffle, reveal, insulation filling and surround surfaces were measured on both cold and warm sides, along with the heat power supplied by the radiators. Then, the calculations given by the Standard EN 12412-2 [11] were performed to obtain the value of the window frame thermal transmittance.

The view of the tested window frame filled with the insulation panel and mounted into the surrounding panel in the calorimetric chamber of the Laboratory of Thermal Engineering at Cracow University of Technology is shown in Figure 8.

The uncertainty of the frame section was calculated using the error propagation rule from the equation:

$$
\Delta \mathrm{U}_{\mathrm{f}}=\sqrt{\left(\frac{\Delta \mathrm{U}_{\mathrm{m}, \mathrm{t}} \partial \mathrm{U}_{\mathrm{f}}}{\partial \mathrm{U}_{\mathrm{m}, \mathrm{t}}}\right)^{2}+\left(\frac{\Delta \mathrm{A}_{\mathrm{t}} \partial \mathrm{U}_{\mathrm{f}}}{\partial \mathrm{A}_{\mathrm{t}}}\right)^{2}+\cdots+\left(\frac{\Delta \theta_{\mathrm{n}} \partial \mathrm{U}_{\mathrm{f}}}{\partial \theta_{\mathrm{n}}}\right)^{2}},
$$

where the uncertainties of all the quantities of Equation (3) had to be calculated according to the error propagation rule. The measured frame thermal transmittance results equaled to $1.063 \mathrm{~W} /\left(\mathrm{m}^{2} \mathrm{~K}\right)$, with an uncertainty of about $8 \%$. 
The discrepancy between the measured and simulated Ansys Fluent values of the frames thermal transmittance was about $3 \%$. The good agreement of measurements with the simulations enforces the reliability of the finite volume analysis for the evaluation of window frames thermal performance.

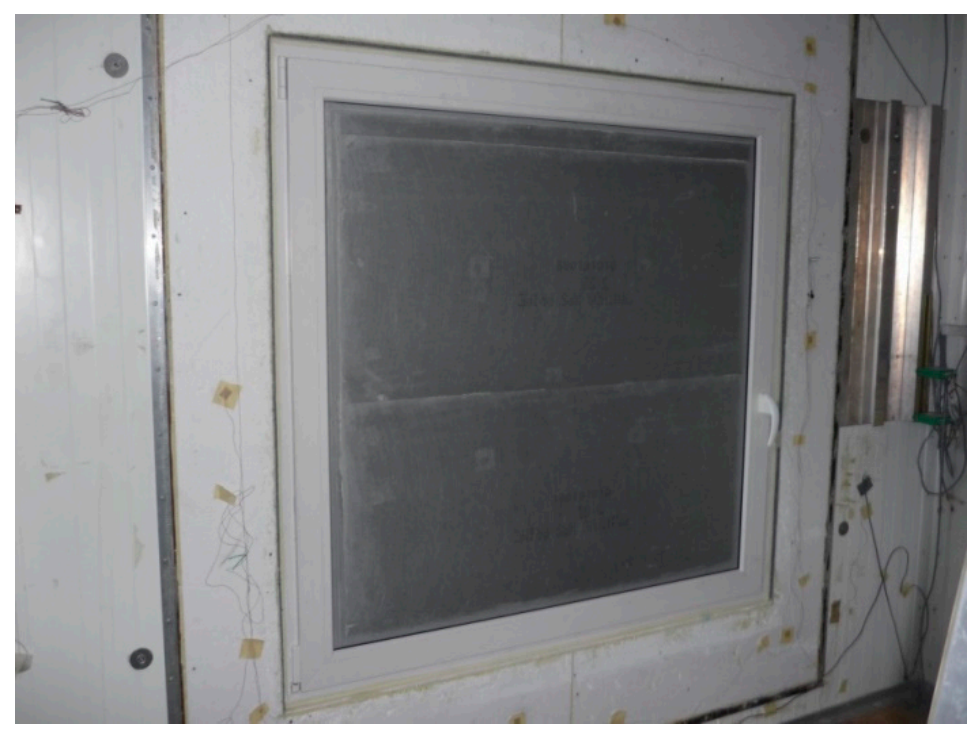

Figure 8. View of the tested window frame in the surround panel on the warm side.

The measurement results as well as the calculation results based on the Standard EN 12412-2 [11] are given in Table 3.

Table 3. Measurement and calculation results of real frame thermal transmittance.

\begin{tabular}{lcc}
\hline \multicolumn{1}{c}{ Quantity } & Value & Unit \\
\hline Air temperature, cold side & 0.7 & ${ }^{\circ} \mathrm{C}$ \\
\hline Baffle temperature, cold side & 0.6 & ${ }^{\circ} \mathrm{C}$ \\
\hline Reveal temperature, cold side & 1.2 & ${ }^{\circ} \mathrm{C}$ \\
\hline Insulation filling temperature, cold side & 1.4 & ${ }^{\circ} \mathrm{C}$ \\
\hline Surrounding panel temperature, cold side & 1.1 & ${ }^{\circ} \mathrm{C}$ \\
\hline Air velocity, cold side & 1.5 & $\mathrm{~m} / \mathrm{s}$ \\
\hline Air temperature, warm side & 19.8 & ${ }^{\circ} \mathrm{C}$ \\
\hline Baffle temperature, warm side & 19.5 & ${ }^{\circ} \mathrm{C}$ \\
\hline Reveal temperature, warm side & 18.0 & ${ }^{\circ} \mathrm{C}$ \\
\hline Insulation filling temperature, warm side & 18.1 & ${ }^{\circ} \mathrm{C}$ \\
\hline Surrounding panel temperature, warm side & 19.0 & ${ }^{\circ} \mathrm{C}$ \\
\hline Air velocity, warm side & 0.1 & $\mathrm{~m} / \mathrm{s}$ \\
\hline Heat power in the hot box & 33.2 & ${ }^{\mathrm{W}}$ \\
\hline Density of heat flow rate through the specimen & 12.5 & $\mathrm{~W} / \mathrm{m}{ }^{2}$ \\
\hline Surround panel thermal resistance & 5.6 & $\mathrm{~m}{ }^{2} \mathrm{~K} / \mathrm{W}$ \\
\hline Total surface heat transfer resistance & 0.26 & $\mathrm{~m}^{2} \mathrm{~K} / \mathrm{W}$ \\
\hline Environmental temperature, warm side & 19.5 & ${ }^{\circ} \mathrm{C}$ \\
\hline Environmental temperature, cold side & 0.7 & ${ }^{\circ} \mathrm{C}$ \\
\hline Frame thermal transmittance & 1.063 & $\mathrm{~W} /\left(\mathrm{m}^{2} \mathrm{~K}\right)$ \\
\hline Frame thermal transmittance uncertainty & 0.089 & $\mathrm{~W} /\left(\mathrm{m}^{2} \mathrm{~K}\right)$ \\
\hline
\end{tabular}




\section{Sensitivity Analysis of the Influence of Input Data on the Value of Window Frames Thermal Transmittance}

In this section, after the simulation code validation, analysis of the influence of input data on the results of window frames thermal transmittance value was performed. The geometry presented in Figure 2 (frame D3 from the Standard [10]) was chosen for the analysis. This is a PVC frame with steel reinforcements, EPDM seals and 11 air gaps within its geometry.

The analysis was performed using Ansys DesignXplorer [14]. This tool enabled us to parameterize the desired input data in Fluent in the assumed range of variations in order to achieve the response surface and to analyze the optimized outputs. The response surface can be used to predict the performance of the data without needing to run the actual simulation. This model was applied for the sensitivity analysis. In the present study, the sensitivity analysis method called "screening" was applied. By means of this approach, it was determined how the change of the input values of a certain parameter influenced the output. The sensitivity is a quotient where the nominator is the difference between the output values $Y(X+D)$ and $Y(X)$, where $D$ is a percentage variation of the input $X$ and it is the term on the denominator. The higher the sensitivity, the higher the impact of the analyzed variable.

In order to prepare the optimization process, it was necessary to create variable input parameters in a given range instead of constant values. The parametric calculations took into account thermal conductivities of the solid materials as well as the surface heat transfer coefficients both on cold and warm frame sides. Moreover, the thermal conductivities of air gaps in the frame were treated as changeable parameters as well. The Standard [10] introduces the method of calculating the equivalent thermal conductivities of air gaps within the frame geometries, considering one-dimensional convective and radiative heat transfer through the gas gaps. As a result, the gap thermal equivalent conductivity treats the gas as a solid material and these values constituted the input data in Ansys Fluent [14] calculations for the frame thermal transmittance. In order to perform the sensitivity calculations, it was necessary to create user defined functions (UDF) in $\mathrm{C}^{++}$to calculate equivalent conductivities of air gaps in Fluent, based on pre-run established gap temperatures and emissivity, which were imported to the UDF by a get-parameter function. These values were then parameterized in Design Explorer. The output parameters were the heat fluxes on the boundary surfaces and a frame U-value that was set as the optimized parameter. The ranges of the variable parameters used for the sensitivity analysis are listed in Table 4.

Table 4. Ranges of parameters variation in the sensitivity analysis.

\begin{tabular}{ccc}
\hline Parameter & Design Value & Range of Variation \\
\hline $\begin{array}{c}\text { P1: surface heat transfer coefficient, cold } \\
\text { side, } \mathrm{W} /\left(\mathrm{m}^{2} \mathrm{~K}\right)\end{array}$ & 25.0 & $10.0-40.0$ \\
\hline $\begin{array}{c}\text { P2: surface heat transfer coefficient, warm } \\
\text { side, } \mathrm{W} /\left(\mathrm{m}^{2} \mathrm{~K}\right)\end{array}$ & 7.7 & $5.0-10.0$ \\
\hline P3: PVC thermal conductivity, $\mathrm{W} /(\mathrm{mK})$ & 0.16 & $0.10-0.20$ \\
\hline P4: surface emissivity of air gaps & 0.90 & $0.10-0.90$ \\
\hline
\end{tabular}

The preliminary sensitivity calculations indicated that thermal conductivities of steel and EPDM have no influence on the results, mainly because of the low amount of these materials in the whole geometry. For this reason, among all the solids, only PVC conductivity was varied in the sensitivity calculation process.

The sensitivities of four output parameters described in Table 4, as calculated in Ansys Fluent [14], are given in Figure 9. A higher parameter sensitivity value means that it has a bigger impact on the output results. 


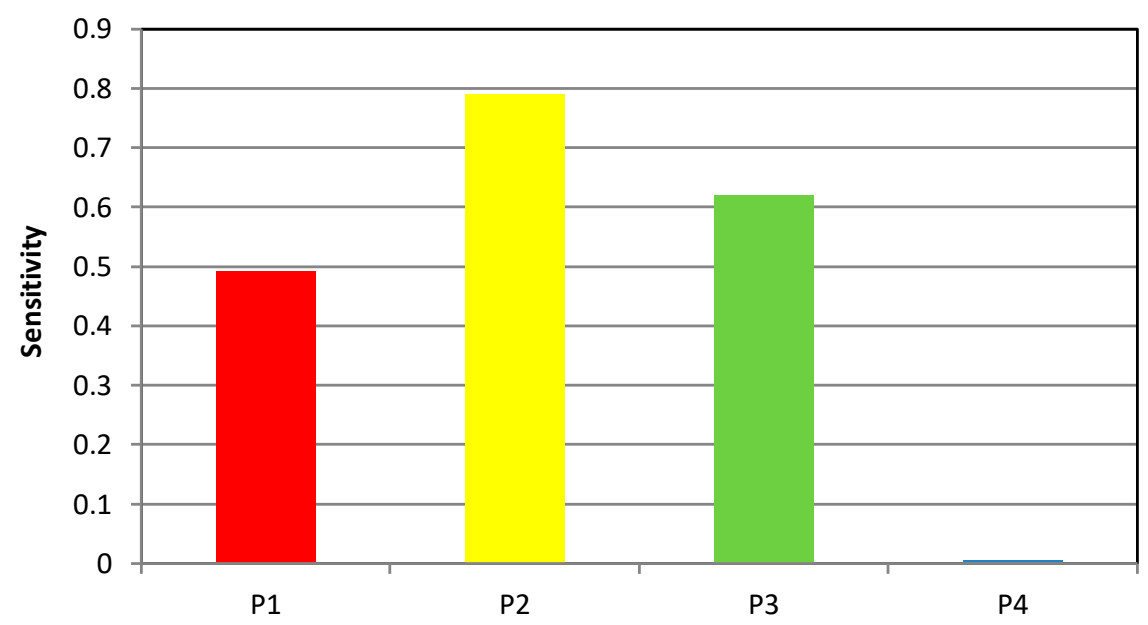

Figure 9. Sensitivities of parameters P1-P4, described in Table 4.

The results indicated that the values of heat transfer coefficients on cold and warm frame sides have dominant impact on the results of frame thermal conductivities together with the PVC thermal conductivity, while the air gaps emissivity alone has a negligible effect on the whole performance.

The surface heat transfer coefficients depend mainly on the air velocity and, at a lower level, on the inner and outer surfaces emissivity. Therefore, their prominent modifications are linked to the convection heat transfer, an effect not tunable by the window frame construction.

The rationing is not to include parameters not directly connected to the building component on the evaluation of its performance. Thus, in the last part of the sensitivity analysis, they were kept constant.

For the same reason, the temperature variations on both cold and warm sides were not investigated, despite the fact that inner and outer temperatures change significantly depending on building location and weather conditions. These temperatures vary quickly in time, especially in the hot season.

On the other hand, the effect of the air gaps equivalent thermal conductivity variation had a substantial impact on the window frame thermal transmittance. It was varied between the worst condition (air in the gap and surface emissivity equal to 0.90) and the most efficient one (which represents the situation of air gaps filled with a super insulation material). Intermediate values may represent filling air gaps with different insulation materials like wool, aerogel or different gases like argon, and giving the surfaces different emissivity [18].

The results of this part of the optimization process indicated that the values of equivalent thermal conductivities of gaps (P5) have the strongest influence on thermal transmittance of window frames with respect to the PVC thermal conductivity (Figure 10).

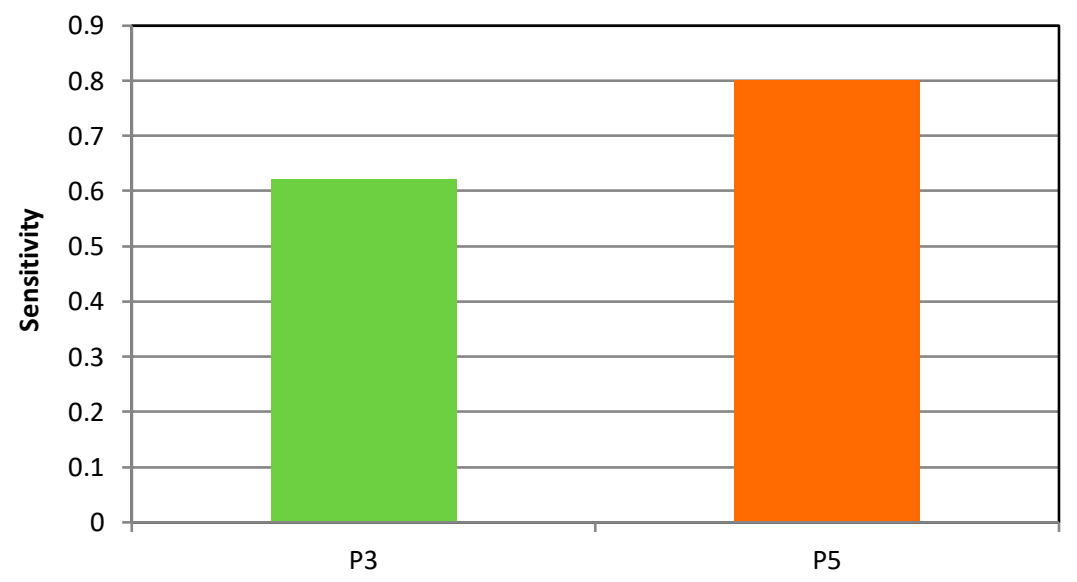

Figure 10. Sensitivities of PVC thermal conductivity (P3) and multiplier of air gap equivalent conductivity (P5). 
Summing up the sensitivity analysis results, both window frame construction and external environmental boundaries considerably influence its thermal performance, with the gaps playing the most important role among the parameters where a designer could intervene.

\section{Conclusions}

The finite volume analysis implemented by a commercial code for the windows frame thermal transmittance numerical assessment proved reliable (discrepancy lower than $3 \%$ ) both from comparison with Standard indications and from experimental validation obtained from a calorimetric chamber apparatus.

The software has been used to perform a sensitivity analysis of the input data (material conductivities, internal and external surface heat transfer coefficients, surface emissivity) on the results of a PVC triple glazing window frame thermal transmittance. The objective consisted of evaluating the influence of each parameter on the global performance of the frame.

The method proved particularly effective, as it allows one to change the input parameters, spanning between reasonable input values, then looking at the changing results. The procedure is implemented with a relatively low computational effort and it seems original, at least in the field of window thermal properties assessment.

The specific outcomes for the case analyzed indicate that it is worth focusing on air gap properties, which could lead to significant improvements if adequately treated. For instance, filling the gaps with an insulation material, substituting the air with a lower conductivity gas such as argon and covering the gap walls with low-emissivity coatings. Beyond the peculiarity value of these results, the proposed numerical optimization methodology could represent a useful tool for window designers and manufacturers to address their energies towards the most fruitful actions for the enhancement of the building components performance.

Author Contributions: G.B., A.L., F.B. and J.S. have contributed equally to the paper. All authors have read and agreed to the published version of the manuscript.

Funding: This research received no external funding.

Conflicts of Interest: The authors declare no conflict of interest.

\section{Nomenclature}

$\begin{array}{ll}\mathrm{A}_{\mathrm{f}} & \text { Frame area, } \mathrm{m}^{2} \\ \mathrm{~A}_{\mathrm{fi}} & \text { Area of the frame filling, } \mathrm{m}^{2} \\ \mathrm{~A}_{\mathrm{t}} & \text { Surface of project of measurement area, } \mathrm{m}^{2} \\ \mathrm{~b}_{\mathrm{f}} & \text { Width of the frame section, } \mathrm{m} \\ \mathrm{b}_{\mathrm{p}} & \text { Visible width of the insulation panel, } \mathrm{m} \\ \mathrm{L}_{\mathrm{f}}^{2 \mathrm{D}} & \text { Thermal conductance of the entire model, } \mathrm{W} /(\mathrm{mK}) \\ \mathrm{U}_{\mathrm{f}} & \text { Frame thermal transmittance, } \mathrm{W} /\left(\mathrm{m}^{2} \mathrm{~K}\right) \\ \mathrm{U}_{\mathrm{m}, \mathrm{t}} & \text { Measured thermal transmittance of frame and insulation filling, } \mathrm{W} /\left(\mathrm{m}^{2} \mathrm{~K}\right) \\ \mathrm{U}_{\mathrm{p}} & \text { Insulation panel thermal transmittance, } \mathrm{W} /\left(\mathrm{m}^{2} \mathrm{~K}\right) \\ \Delta \theta_{\mathrm{n}} & \text { Environmental temperature difference, } \mathrm{K} \\ \Delta \theta_{\mathrm{s}, \mathrm{fi}} & \text { Surface temperature difference on warm and cold sides of the frame filling, } \mathrm{K} \\ \Phi & \text { Linear heat flow rate, } \mathrm{W} / \mathrm{m} \\ \Lambda_{\mathrm{fi}} & \text { Thermal conductance of the frame filling, } \mathrm{W} /\left(\mathrm{m}^{2} \mathrm{~K}\right) \\ \theta_{\mathrm{e}} & \text { External air temperature, }{ }^{\circ} \mathrm{C} \\ \theta_{\mathrm{i}} & \text { Internal air temperature, }{ }^{\circ} \mathrm{C}\end{array}$

\section{References}

1. Gustavsen, A.; Grynning, S.; Arasteh, D.; Jelle, B.P.; Goudey, H. Key elements of and material performance targets for highly insulating window frames. Energy Build. 2011, 43, 2583-2594. [CrossRef] 
2. Ihm, P.; Park, L.; Krarti, M.; Seo, D. Impact of window selection on the energy performance of residential buildings in South Korea. Energy Policy 2012, 44, 1-9. [CrossRef]

3. Larsson, U.; Moshfegh, B.; Sandberg, M. Thermal analysis of super insulated windows (numerical and experimental investigations). Energy Build. 1999, 29, 121-128. [CrossRef]

4. van der Bergh, S.; Hart, R.; Jelle, B.P.; Gustavsen, A. Window spacers and edge seals in insulating glass units: A state-of-the-art review and future perspectives. Energy Build. 2013, 43, 263-280. [CrossRef]

5. Thalfeldt, M.; Kurnitski, J.; Voll, H. Detailed and simplified window model and opening effects on optimal window size and heating need. Energy Build. 2016, 127, 242-251. [CrossRef]

6. Yang, Z.; Katsura, T.; Aihara, M.; Nakamura, M.; Nagano, K. Investigation into Window Insulation Retrofitting of Existing Buildings Using Thin and Translucent Frame-Structure Vacuum Insulation Panels. Energies 2018, 11, 298. [CrossRef]

7. Koo, S.Y.; Park, S.; Song, J.-H.; Song, S.-Y. Effect of Surface Thermal Resistance on the Simulation Accuracy of the Condensation Risk Assessment for a High-Performance Window. Energies 2018, 11, 382. [CrossRef]

8. Park, S.; Song, S.-Y. Evaluation of Alternatives for Improving the Thermal Resistance of Window Glazing Edges. Energies 2019, 12, 244. [CrossRef]

9. Baldinelli, G.; Asdrubali, F.; Baldassarri, C.; Bianchi, F.; D’Alessandro, F.; Schiavoni, S.; Basilicata, C. Energy and environmental performance optimisation of a wooden window: A holistic approach. Energy Build. 2014, 79, 114-131. [CrossRef]

10. ISO 10077-2. Thermal Performance of Windows, Doors and Shutters-Calculation of Thermal Transmittance-Part 2: Numerical Method for Frames; International Organization for Standardization: Geneva, Switzerland, 2017.

11. EN 12412-2. Thermal Performance of Windows, Doors and Shutters-Determination of Thermal Transmittance by Hot Box Method-Frames; European Standarization Organization: Brussels, Belgium, 2003.

12. Available online: https://www.dartwin.it/sw/frame-simulator/ (accessed on 20 February 2020).

13. Available online: https://windows.lbl.gov/tools/therm/software-download (accessed on 20 February 2020).

14. ANSYS, Inc. Products 2019 R1; ANSYS: Canonsburg, PA, USA, 2019.

15. Zajas, J.; Heiselberg, P. Parametric study and multi objective optimisation of window frame geometry. Build. Simul. 2014, 7, 579-593. [CrossRef]

16. Lechowska, A.; Schnotale, J.; Baldinelli, G. Window frame thermal transmittance improvements without frame geometry variations: An experimentally validated CFD analysis. Energy Build. 2017, 145, 188-199. [CrossRef]

17. Lechowska, A.; Schnotale, J. Thermal transmittance of multi-layer glazing with ultrathin internal partitions. In Proceedings of the from BS2015: 14th Conference of International Building Performance Simulation Association, Hyderabad, India, 7-9 December 2015.

18. Asdrubali, F.; Baldinelli, G.; Bianchi, F. Influence of cavities geometric and emissivity properties on the overall thermal performance of aluminum frames for window. Energy Build. 2013, 60, 298-309. [CrossRef] 